\title{
Bucear en los archivos
}

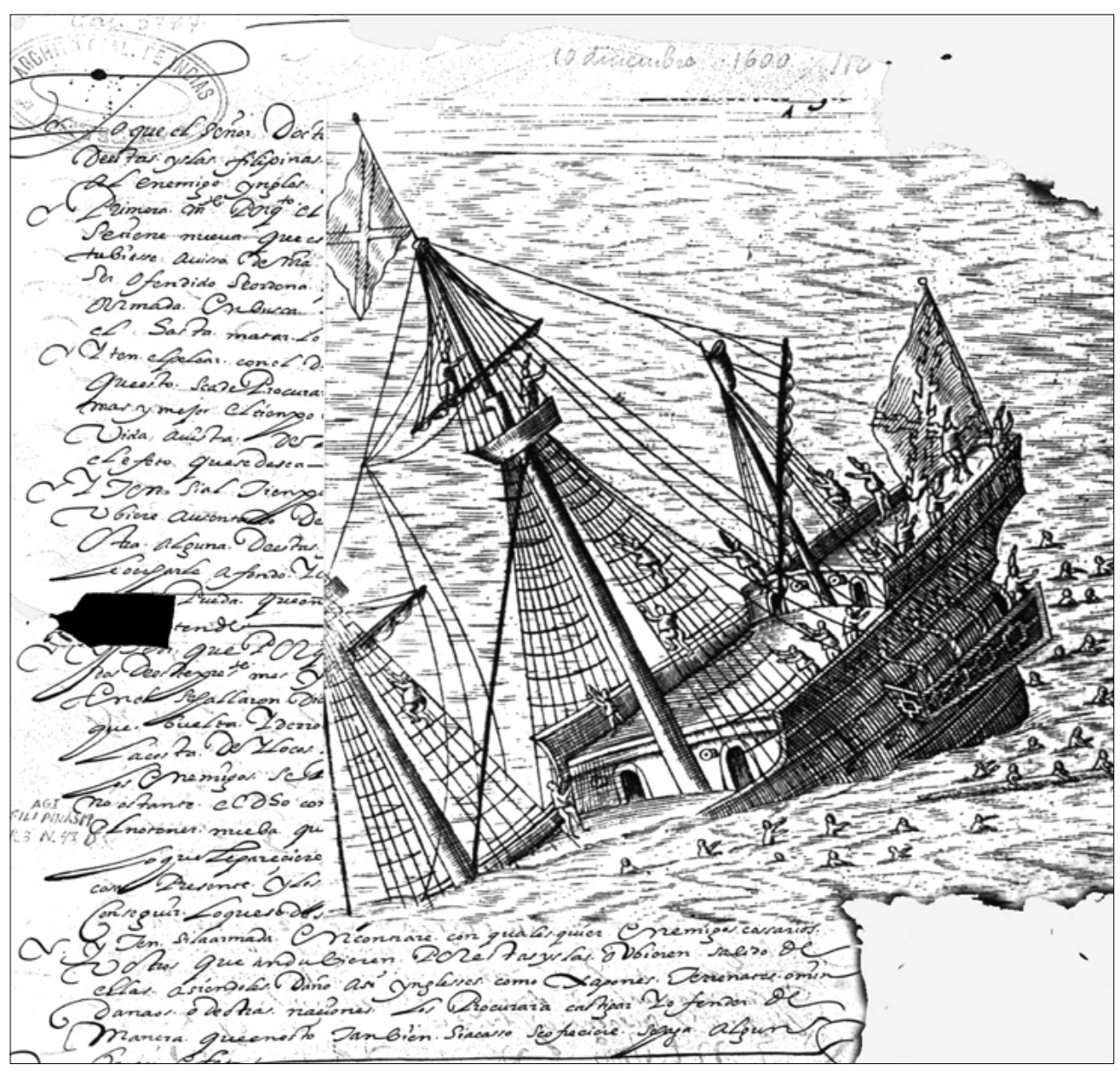

\section{Genoveva Enríquez Macías}

Licenciada en Historia de América por la Universidad de Sevilla
La versión preliminar de este artículo fue originalmente publicada en la revista argentina Noticias de Antropología y Arqueología -ISSN 0329-0735, Web: www.naya.org.ar-. PH agradece al Equipo NayA, a la coordinadora de la edición del cd "Arqueología Subacuática", Mónica Patricia Valentini, y a la autora su desinteresada colaboración.
Los archivos históricos siempre han sido considerados por la gente en general como un lugar, más o menos polvoriento, pero desde luego aburrido. En los últimos años esta idea va cambiando gracias al auge de la novela histórica y a la publicidad que se ha dado a un nuevo fenómeno: los cazadores de tesoros. Entre los papeles viejos de los legajos podemos encontrar historias fantásticas y aventuras que jamás será superadas por el mejor guión cinematográfico, y sin duda unas de las más apasionantes para investigar son los naufragios.

Tenemos que reconocer una verdad aunque nos duela: los cazatesoros han sido los promotores de la Arqueología Subacuática en los trabajos que se refieren a la época Moderna y Contemporánea, y con ellos se ha despertado también el interés por rastrear los archivos en busca de tesoros perdidos. Cuando los profesionales de la Historia (me refiero a titulados universitarios, a los que tienen formación académica) empezaron a asistir impotentes al espectáculo de los 
galeones expoliados, a la nula consideración que ciertos países daban a su patrimonio cultural sumergido $y$, en fin, al mercadeo de la Historia, se generó una conciencia de protección y un interés por estudiar ese patrimonio que hasta entonces había estado olvidado, o simplemente ignorado.

Después de todo, a Mel Fisher tenemos algo que agradecerle: que sacara a la luz ese potencial inmenso y desconocido. El Atocha fue el pistoletazo de salida para los aventureros sin escrúpulos y las consecuencias no han sido desde luego positivas, pero han generado también una reacción de los arqueólogos para evitar la expoliación, y con ello el desarrollo de todas las disciplinas que confluyen en este campo de trabajo.

Los avances tecnológicos en prospecciones submarinas también les ayudaron y motivaron, pues hasta hace pocos años los estudiantes de Arqueología sólo soñaban con trabajar en el Valle de los Reyes de Egipto. Ninguno se imaginaba buceando como Cousteau, porque eso requería unas condiciones físicas, un entrenamiento y material específico y unas técnicas de trabajo que no conocían, aparte de resultar un trabajo más duro. Sólo centraban su atención en los restos guardados bajo tierra y en seco.

Un campo nuevo, virgen y con enormes posibilidades, se abría ante distintos especialistas de la Historia. Los puramente historiadores, los que se dedicaban a investigar en archivos y bibliotecas reconstruyendo el pasado a partir del documento escrito, empezaron a ser requeridos para hacer investigaciones sobre galeones perdidos.

Y esta es una idea que me gustaría destacar especialmente: para un barco fenicio no contamos con testimonios escritos que ilustren y expliquen por qué se perdió, pero para un galeón español del XVII podemos tener la suerte de encontrar cientos de páginas que describan minuciosamente cómo estaba construido, cómo eran sus aparejos, qué llevaba en la bodega, cómo eran los cañones que lo defendían, quiénes eran los tripulantes y pasajeros, qué comieron durante el viaje, qué llevaban en sus baúles, cuál fue la causa de su naufragio y cuántos viajes hizo ese buque hasta que desapareció. No tener en cuenta toda esta información significa que el arqueólogo se puede quedar con un trozo de madera en las manos, y nada más. Podrá analizar la madera y el entorno donde la encontró con otros restos, pero los datos que obtenga de ella serán muy limitados sin un contexto donde enmarcarlos.

En los comienzos sólo los cazatesoros estuvieron interesados en los archivos. También en esto abrieron un camino, pero ellos sólo buscaban datos concretos: lugar de la pérdida y carga del buque. Todo el contexto histórico, las circunstancias del naufragio y las múltiples posibilidades que ofrecía la documentación, no les importaban en absoluto. No tenían formación académica, ni siquiera unos conocimientos mínimos de la época histórica en que sucedió el naufragio. Su objetivo era rescatar y vender.
Pronto se descubrió que éste era un tremendo negocio. De la misma manera que hay expoliadores de tumbas egipcias o quechuas, aparecieron los expoliadores de galeones hundidos. Y lo más lamentable es que lo hacían en connivencia con los países y gobiernos titulares de las aguas donde se encontraban los pecios. Curiosamente, estos gobiernos consideraban que un galeón hundido no tenía la misma categoría que una pirámide maya. Posiblemente por desconocimiento y por el razonamiento simplista de que estando hundido no era visible ni visitable, y por tanto no generaba beneficios como atracción turística. Sacar esos restos a la luz costaba dinero, no había arqueólogos que supieran bucear, la conservación y restauración de unos restos sumergidos durante siglos en agua salada también estaba en pañales. No había laboratorios ni técnicos especializados. La mayoría de esos galeones estaban en aguas jurisdiccionales de países cuya economía se enmarca en el Tercer Mundo o "países en vía de desarrollo", sin una legislación específica ni una política establecida (no sólo en el papel, sino en la práctica) en cuestión de Patrimonio Histórico Sumergido. Era más fácil darle la concesión a quien estuviera dispuesto a asumir esos gastos, independientemente de su titulación y capacidad para enfrentar el proyecto. Y de paso se le cobraba por la concesión. Ganancias limpias para el país de turno (que solía firmar un convenio con el cazatesoros del tipo "nos lo repartimos al 50\%"), y ganancia dudosa para el inversor, que en principio ponía todo el dinero basándose sólo en el típico sueño de encontrar el famoso cofre del tesoro lleno de barras y monedas de oro y plata. El promotor buscaba inversores y creaba una empresa que incluso llegaba a cotizar en Bolsa, con lo cual se daba el curioso fenómeno de que se publicitaban resultados inflados en todos los medios de comunicación para seguir captando inversores, cuando en realidad no se tenía más que un somero proyecto cuyo objetivo era rescatar un galeón cargado de "oro y diamantes". Se vendía la piel del oso antes de cazarlo.

Pero no nos engañemos, tampoco han tenido tanto éxito (afortunadamente). La impresión general es que por todas partes se están sacando tesoros de galeones perdidos. Sin embargo, de cada diez proyectos que se inician sólo una mínima parte, quizás uno o dos, llegan a culminar. Por dos razones fundamentales:

- De todo el repertorio de naufragios, no todos se pueden localizar con precisión. De los que se pueden localizar, muchos fueron rescatados en la época del naufragio. De los localizables y aún por rescatar, muchos están inaccesibles o suponen una inversión demasiado costosa. El porcentaje se reduce por tanto considerablemente. Existen desde luego los expoliadores sistemáticos, los mismos que para los yacimientos terrestres, gente que dispone de un equipamiento mínimo que les permite bucear en zonas accesibles y no demasiado profundas, a partir de hallazgos casuales o de una información más o menos cierta.

- Pocos cazatesoros inician las prospecciones con una investigación histórica previa que les aporte todos los datos necesarios para el trabajo. Muchos se lanzan a 


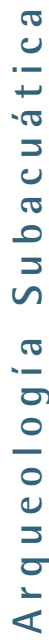

bucear sólo porque tienen una noticia peregrina, a partir de datos proporcionados por pescadores, por algún viejo libro o documento, y en los últimos tiempos por la proliferación de publicaciones sobre naufragios, muchas de ellas producto de los propios cazatesoros. Datos sin confirmar, y en cualquier caso, siempre escuetos e imprecisos. Una vez embarcados en el proyecto se dan cuenta de que no encuentran nada por muy variados motivos: porque el que les vendió la información les mintió, porque el barco que buscan ciertamente se perdió, pero no hundido sino robado por unos piratas... o simplemente porque no han sabido analizar la información que tenían y están buceando inútilmente en un lugar equivocado.

Los archivos históricos, y en particular el Archivo General de Indias de Sevilla, empezaron a generar un interés que iba más allá de lo puramente académico. Aquí se guardaban los documentos que podían dar las pistas de innumerables tesoros. Y así empezó a llegar gente que, sin formación y sin apenas hablar español, pretendían leer papeles del siglo XVI y XVII. La idea general era que todos los naufragios estaban catalogados, que sólo había que presentarse en el Archivo de Indias, preguntar por un barco determinado, y en alguna parte habría un listado de pérdidas de embarcaciones detallando el lugar y la carga. Incluso llegaban con la imagen novelera de que encontrarían el típico mapa con la cruz marcando el lugar donde estaba el pecio. Al cabo de varios días de no entender nada recurrían a quien pudiera ayudarles y comprobaban que para leer documentos del XVI hacía falta un personal especializado. Para leerlos y para encontrarlos, por supuesto.

Al arqueólogo le ha ocurrido lo mismo. Ha comprobado que todo resulta más fácil si dispone de una información previa sobre el barco que va a prospectar: para localizar los restos con la mayor precisión posible, para tener una idea de lo que puede encontrar bajo el agua, para identificar los objetos que vayan apareciendo, y para tener una información adicional a la hora de analizarlos cuando se inicie el proceso de conservación y catalogación. Y se convencen de que,

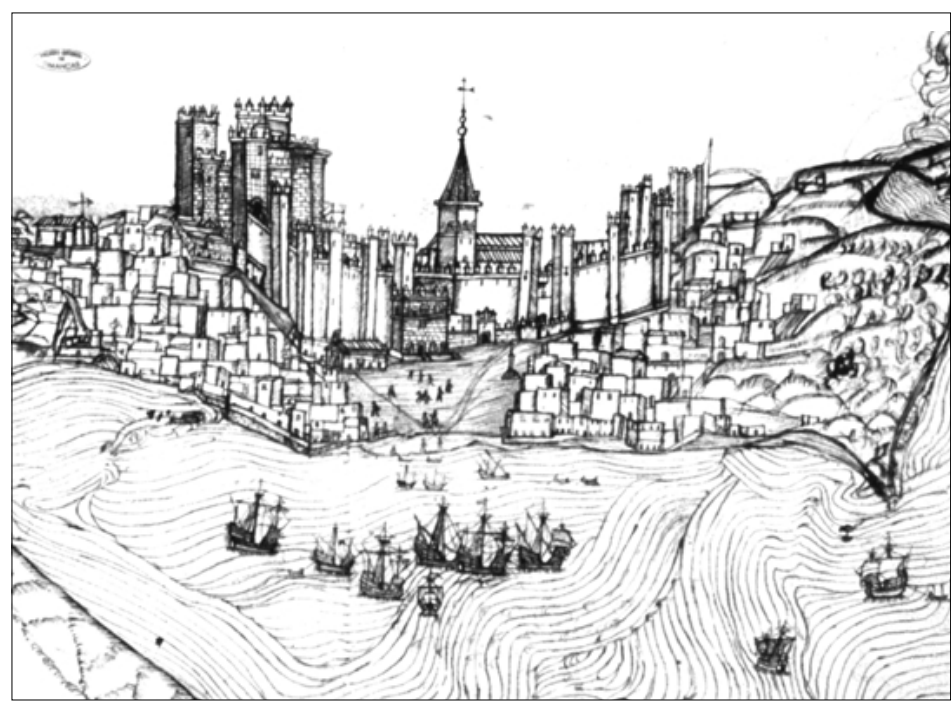

con una información histórica que explique el qué, cómo, cuándo, quién y por qué.... se podrá hacer un estudio y una publicación de los resultados con mayor riqueza y rigor científico.

\section{¿Cómo se busca un naufragio en los archivos?}

Hay dos posibles puntos de partida:

- Documentar un naufragio concreto.

- Hacer una carta arqueológica de una zona más o menos extensa, incluso de un país al completo.

Para el primer caso nos bastaría con unos datos mínimos: fecha y lugar aproximado de la pérdida, o el nombre de la embarcación, o el del general de la flota... Mientras más datos podamos reunir en un principio más fácil lo tendremos, eso es evidente. La información que pueda existir es siempre un misterio. Barcos que aparentemente, por su importancia, tendrían que estar muy documentados, finalmente nos decepcionan porque apenas hay cuatro líneas sobre ellos. Las causas pueden ser variadas:

- Porque no se hizo una información sobre la pérdida cuando ésta se produjo, bien porque no hubo supervivientes que pudieran dar testimonio, o bien porque por diversos intereses se decidió no informar a las autoridades. Si no se informa no hay noticias y se puede robar entre los restos.

- Porque los documentos han desaparecido o no están en los Archivos que visitamos. A lo largo de los siglos los avatares sufridos por la documentación son inimaginables.

- Porque la pérdida se produjo en un lugar deshabitado o habitado sólo por población indígena, alejado de centros de población con españoles, que son los que escriben y dan noticias de un suceso.

- Porque el naufragio se produjo en alta mar, demasiado alejado de la costa como para tener un punto de referencia terrestre que nos permita situar el lugar de la pérdida. No olvidemos que las coordenadas náuticas varían según las épocas, normalmente no sabemos el meridiano que sirve de referencia para hacer la medición, los instrumentos náuticos eran imprecisos y, aplicando una dosis mínima de lógica, hay que imaginar que si el naufragio se produjo a causa de una fuerte tormenta o un huracán, los afectados no tendrían ni tiempo para medir su altura y fijar su posición, que en cualquier caso nos valdría de poco porque en esas condiciones la embarcación sería llevada a merced del temporal.

Esto nos deja con la única posibilidad fiable: sólo un punto de referencia terrestre nos ayudará a localizar el barco. Un cabo, una montaña en el horizonte, unos arrecifes.... A veces lo podemos calcular por el camino que recorrieron los supervivientes hasta llegar a un nú- 
cleo de población. Ningún dato se puede pasar por alto ni es desdeñable. Será más fácil si la pérdida se produjo en una zona muy poblada y conocida como la costa andaluza, y más difícil si se trata de una isla deshabitada de las Filipinas. Pero cuando menos lo esperas y donde menos te imaginas, encuentras ese dato importante que te resuelve una incógnita.

En este punto conviene señalar algo importante: los topónimos varían, cambian y desaparecen a través del tiempo. También se repiten algunos dentro del mismo país o en diferentes países. Podemos encontrar varios cabos Gracias a Dios, o Tiburón, por ejemplo. Es esencial y condición indispensable contar con un buen repertorio de mapas de la zona que nos interese, desde los actuales más detallados, hasta los antiguos que señalen los topónimos usados en la época. Hay que ir contrastando hasta llegar a situar el lugar que buscamos. También son muy útiles las obras publicadas en el siglo XIX y principios del XX, cuando se pusieron de moda los libros de viajes con información detalladísima al estilo etnográfico. Son obras muy descriptivas y suelen contar con mapas. Tampoco hay que descartar las obras procedentes de Órdenes religiosas, porque solían hacer historias muy pormenorizadas y, por supuesto, los frailes también viajaban en los galeones y son una fuente de información.

Lo recomendable es transcribir los documentos literalmente, o pasándolos al castellano actual para facilitar la lectura posterior del informe. Pero en cualquier caso hay que tener cuidado cuando transcribimos datos sobre coordenadas o topónimos. A menos que esté muy claro en el papel, es mejor hacer una transcripción literal, que luego podrá ser cotejada. Sobre todo si el investigador no es un experto paleógrafo. Entonces lo mejor es encargar fotocopias del documento y pedir la colaboración de otros expertos. Una simple letra puede enviar al equipo de prospección en una dirección opuesta. Por ejemplo: "est" o "uest", sólo una letra diferencia el este del oeste, y hay que tener en cuenta que si leemos documentos de los siglos XVI y XVII, no había entonces una ortografía fijada y cada cual escribía de oídas. Por no mencionar que los documentos tampoco están escritos a máquina y que todo depende de la mejor o peor letra del que los escribió. Unas palabras se unen con otras.... la procesal encadenada es como una madeja que hay que desenredar y las abreviaturas martirizan al paleógrafo más experto.

De manera que, para evitar pasar por alto cualquier dato, lo mejor es transcribir todo aquello que se relacione, de cerca o de lejos, con el hecho que estamos investigando. Una declaración del general de la flota es desde luego importante, pero no lo será menos la de un simple marinero o grumete, incluso a veces ésta es la que nos da la clave de lo que buscamos.

Hay que estar siempre pendiente del contexto en que se produce un naufragio, esto nos dará el marco para explicarnos muchas de las cosas que no entendamos o que nos parezcan ilógicas. No olvidemos que nuestra concepción del tiempo y del espacio no tiene nada que ver con la que se tenía en siglos pasa- dos. $Y$ de todas formas siempre nos encontraremos con expresiones que no sabremos descifrar, como la de "se perdió a un tiro de arcabuz de la costa" ¿A qué equivale eso en la actualidad?

Tomar todos lo datos por sistema nos ahorrará tener que volver al documento para recordar aquello que quedó difuso en nuestra memoria, y que al cabo de unos días de investigación se convierte en una información esencial.

Hay que tomar nota de todos los nombres que vayan apareciendo, porque son personas implicadas que, quizás años después de la pérdida del barco, iniciarán un pleito por aquel suceso y nos darán una información incalculable.

Estas son las recomendaciones básicas para investigar a fondo un naufragio. Pero si lo que debemos hacer es una carta arqueológica, entonces el objetivo es elaborar una especie de catálogo con información concreta y precisa. No queremos decir que haya que leer menos documentos, pero no será necesario transcribir todo. Bastará con ir leyendo, hacer anotaciones y un resumen que permitan localizar la pérdida y tener unos datos mínimos sobre el caso. Quizás después, según las necesidades del proyecto que se ponga en marcha, se pasará a profundizar con más detalle, aplicando todo lo expuesto más arriba.

Finalmente, el requisito imprescindible es saber Paleografía, saber descifrar la escritura de un documento. Sin esos conocimientos será muy difícil leer, entender y transcribir fiablemente un papel de hace cuatro siglos.

\section{¿Dónde encontramos información?}

Cada Archivo es un mundo y está organizado de una manera diferente según los fondos que contenga. La experiencia del investigador será una ventaja inestimable, no es lo mismo pisar por primera vez un Archivo que hacerlo cuando ya se tienen años de investigación histórica a las espaldas. Como ocurre en cualquier trabajo y en cualquier profesión. Pero hay algo básico: conocer el periodo histórico que vamos a trabajar, y sobre todo el funcionamiento de la Administración de la época. Si sabemos cuáles eran las instituciones productoras o receptoras de información sabremos cuál es el circuito que seguían los papeles de un funcionario a otro, dónde se guardaron. Un Archivo debe mantener siempre el respeto a la procedencia de los documentos, es decir, si se pusieron allí en un determinado orden, así deben seguir porque eso responde a una organización administrativa concreta de la época en que fueron producidos. Y esto nos ayuda a localizarlos en la actualidad.

Cada Archivo debe tener una guía básica para el usuario, unos inventarios de las distintas secciones y a poder ser unos catálogos documentales. Todos ellos nos irán llevando por su organización interna y nos ayudarán a localizar lo que buscamos. Por supuesto, 


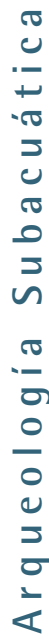

las referencias en libros publicados son un buen punto de partida para encontrar los documentos, pero éstas deben ser siempre comprobadas... sobre todo si de naufragios se trata.

Podemos poner el ejemplo del Archivo de Indias, pero en realidad sólo hay que aplicar un poco de lógica para establecer en qué secciones de cualquier otro Archivo conviene empezar la investigación. En primer lugar, serían las autoridades locales del lugar donde se produjo el naufragio las que informarían sobre la pérdida a su inmediato superior. Luego éste informaría a su vez a otro de más arriba, quizás ya con unos datos más amplios si se ocupó de enterarse de lo sucedido por testigos o implicados. Puede que se hiciera una investigación detallada con declaraciones si la pérdida se atribuye a un fallo humano, como por ejemplo, a impericia del piloto. $Y$ en estos casos podemos encontrar hasta un enorme pleito judicial con información jugosa, porque muchos intereses están en juego y todos reclaman para que se les indemnice. Exactamente lo mismo que ocurriría ahora en un caso similar. Se enviaba un comisionado al lugar, se interrogaba a testigos y afectados, etc, por eso en secciones del Archivo de Indias como "Escribanía" o "Justicia" podemos encontrar legajos enteros sobre un naufragio. Cuando se trate de una pérdida a consecuencia de una batalla naval quizás esté más documentado, al convertirse en un hecho de armas del que se informa profusamente para ensalzar la victoria o para justificar la derrota.

En el caso de la Carrera de Indias, de las embarcaciones que navegaban comunicando España con sus posesiones de Ultramar, esa información que se genera en América o Filipinas debía pasar a la metrópoli, sobre todo si se trataba de una embarcación importante y la pérdida fue de consideración. Si el barco salió de Cádiz y se perdió en aguas americanas, tendremos que reproducir el viaje para ir reuniendo información: los preparativos para el despacho de la flota, su carga, etc. Y lo mismo cuando es en sentido contrario; si el barco salió de San Juan de Ulúa, hizo escala en La Habana y se perdió en la barra de Sanlúcar, tendremos que ir rastreando papeles por este camino.

Sería demasiado extenso explicar los pormenores de esa Carrera, y las múltiples variantes y peculiaridades que presenta el panorama naval de la época colonial. Hay zonas que podríamos llamar de "primera categoría", aquellas donde se localizan los puertos importantes de la Carrera que funcionaban como puerta de entrada y salida en el continente. No hay que olvidar que, igual que Sevilla y luego Cádiz en España, en América también se establecieron unos puertos concretos para la llegada y salida de las embarcaciones. Y así, las aguas que eran navegadas por las grandes flotas y armadas, la de Nueva España (a México) y la de Tierra Firme (a Colombia y Panamá), básicamente, son las que más posibilidades tienen de registrar naufragios. Se marcaron una especie de autopistas o rutas principales, con ramales a puertos secundarios. Por otra parte, existían paralelamente otras rutas secundarias que conectaban con las principales, como el caso de los puertos del Pacífico (Chile, Ecuador, Perú) cuyas cargas se llevaban a la costa de Panamá, cruzaban el istmo en recuas de mulas o por el río Chagre, y luego eran embarcadas en la flota de Tierra Firme que las esperaba en los puertos de la costa caribeña. Si se producen pérdidas en este circuito secundario del Pacífico, no conectado directamente con España, la información suele quedar en legajos de las autoridades locales, porque son barcos que no eran registrados por la Casa de la Contratación de Sevilla o Cádiz, salvo cuando ya se abre sistemáticamente el tráfico por el Estrecho de Magallanes y se conecta directamente Europa con el Pacífico.

De manera que hay que tener en cuenta que un barco podía salir de un puerto determinado, pero podía transportar carga de distintas procedencias, y por tanto encontraremos información a partir de todos los lugares donde pudiera haber interesados en esa carga.

Para el caso de naufragios en Andalucía relacionados con la Carrera de Indias, toda la información contenida en la sección "Contratación" es básica. La Casa se ocupaba de registrar todas las entradas y salidas de navíos, pasajeros y cargas, y además sus funcionarios estaban precisamente en el lugar que nos interesa si buscamos un naufragio en la costa andaluza. No sólo se trata de la información que proporciona una investigación sobre los responsables de la pérdida, sino de la generada a partir de las labores de rescate que se pudieron realizar en la época. Los documentos relacionados con un naufragio pueden abarcar varios años dependiendo del tiempo que duraran los trabajos de rescate de la carga.

Otras secciones con documentación sobre naufragios son las de "Indiferente General" (con varias series sobre armadas y flotas y todo lo relacionado con el fenómeno naval) y "Consulados". El Consulado era una institución que agrupaba a los mercaderes censados como tales en cada ciudad, y controlaban todo lo referente al comercio de particulares. En consecuencia, también nos proporciona una información valiosa sobre buques y cargas, así como otras secciones relacionadas con el transporte y comercio marítimo.

Volviendo a la idea central de que un barco era el único medio de transporte y de comunicación, y que igualmente hasta el bien entrado el siglo XX no había otra manera de comunicarse que la oral o escrita, de boca en boca o de mano en mano (no había fax, ni cámaras de fotos o vídeo, ni teléfono, ni e-mail...), la deducción lógica es que todo lo que podemos saber y conocer de esas épocas pasadas tiene que estar escrito o dibujado. Y el barco era el medio de transporte. Por tanto, en cualquier testimonio escrito podemos encontrar información sobre barcos. En una relación de méritos y servicios de un soldado que viajó en un galeón naufragado y que colaboró en las tareas de rescate; en el testimonio de un fraile dominico que consiguió llegar a nado a la costa cuando viajaba a Filipinas y el galeón de Manila se perdió en unos arrecifes; en la viuda de un marinero ahogado durante un temporal en el Estrecho de Gibraltar, y que reclama la paga de 
ese marinero; en la carta de los miembros de un cabildo que se quejan amargamente de la ruina que padece su ciudad por el ataque de unos piratas, que además han echado a pique las naos de la flota. El contexto de un naufragio es tan amplio que la información la podemos encontrar en casi todos los documentos de la época y de las zonas geográficas que se relacionaron directa o indirectamente con él.

Las causas de un naufragio son igualmente variadas: por desconocimiento de la ruta a seguir, por falta de precisión en las cartas náuticas, por un ataque enemigo, por impericia del piloto, por temporal, por sobrecarga, por mal estado del navío, e incluso se dan casos de naufragios intencionados para robar la carga. Todo este abanico de posibilidades genera a su vez un amplio campo de documentación a consultar.

Las mejores expectativas que podemos tener a la hora de iniciar una investigación es que podemos encontrar datos sobre el buque (nombre, tonelaje, construcción, astillero donde se fabricó, materiales utilizados y procedencia de éstos, artillería, munición, armas y aparejos, viajes anteriores, obras y reparaciones que se le hicieron), sus dueños y tripulación (listado completo de la gente de mar y guerra que se embarcó), pasajeros (nombres y equipajes, a veces con el contenido de sus baúles), rancho embarcado para alimentar a tripulación y pasajeros (incluyendo animales vivos), pertrechos y menaje, ruta que siguió, diario de navegación con incidencias de la travesía, carga detallada, dueños y destinatarios de la misma, descripción de las causas del naufragio, lugar de la pérdida e implicación de los que habitaban la zona, relato del suceso, declaraciones de testigos, pleitos posteriores y labores de rescate de la carga.

Evidentemente es excepcional encontrar todo esto para un mismo buque, pero baste esta relación para ilustrar lo que queremos exponer aquí.

No olvidemos tampoco que la experiencia del historiador a la hora de manejar el vocabulario naval de la época será de gran ayuda para dilucidar cuáles fueron las circunstancias y en qué estado o situación quedó el buque naufragado. No es lo mismo "echar a pique"

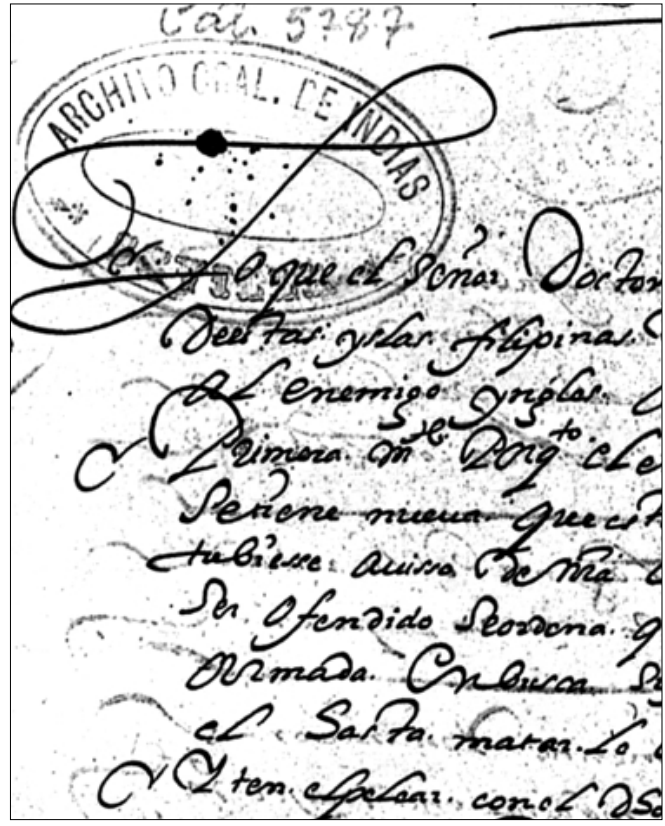

que "se fue a pique", no es lo mismo "encallar", "zabordar", "zozobrar", "irse a fondo", "hundirse"....no es lo mismo "tocar fondo" que "abrirse", "ir al través" que "echar al través". Cada uno de estos términos y expresiones nos da una imagen diferente del suceso. Decir que un barco "se perdió" no significa que estuviera en lugar desconocido, sino que sufrió un accidente que lo inutilizó, hundió, quemó o encalló, en lugar conocido o desconocido.

Los trabajos de Arqueología Subacuática necesitan equipos interdisciplinares, y el papel del historiador es esencial para aportar información a todos los especialistas que participan en ellos. Sólo así podrán trabajar con más datos y los resultados y conclusiones tendrán una visión más amplia, una trascendencia a partir del fenómeno que se estudia en toda su complejidad y extensión. Todos los conocimientos y experiencias son complementarios y, de la misma manera que el arqueólogo bucea para localizar restos sumergidos, el historiador bucea en los archivos para proporcionarle la información escondida en los legajos. 